\title{
INFLUENCE OF EXTERNAL ENVIRONMENTAL FACTORS ON RANGE ESTIMATION OF AUTONOMOUS HYBRID VEHICLES
}

doi: $\quad 10.2478 /$ czoto-2019-0061

Date of submission of the article to the Editor: 11/11/2018

Date of acceptance of the article by the Editor: 29/12/2018

\section{Máté Zöldy ${ }^{1}$}

Imre Zsombók ${ }^{1}$

1BME Budapest University of Technology and Economics, Hungary, zsombok@ak-s.hu

\begin{abstract}
During our research, we focus on a less researched area in the development of autonomous vehicles. Automotive industry is turning more and more from conventional, internal combustion engine equipped vehicles to the electric cars. Today, electric driving is mostly limited to urban traffic, this is the area where range and refueling limits can be a real alternative. However, it is important to think of those who intend to use vehicle in longer distances, and hybrid technology can provide them a modern, environmentally conscious way of transport.

In this article, we describe the method of creating the fuel consumption influencing factors matrix, which is the starting point of our research. We studied relevant researches and based on refueling studies we created the matrix. Based on results of real tests, we determined the factor mix that are the basis of our fuel consumption prediction model. These results will be inputs of planning routes of autonomous vehicles with optimized refueling and fuel consumption.
\end{abstract}

Keywords: hybrid vehicles, electric driving

\section{INTRODUCTION}

Today, the question is not whether self-driving vehicles appear or not, but when they will and how they will affect our lives. Driverless ride on fixed-track vehicles has been for many years and the aerospace industry has taken steps with the autopilot in this direction too. Numerous experiments and researches are being conducted with autonomous vehicles in parallel that simulate and optimize their behavior in traffic situations.

Autonomous vehicles will be decisive if they are not exclusive actors in transport over time, thus completely transforming transport and vehicles participating in it. The technological revolution that derives from their appearance and spread, can be considered the biggest turning point in the history of transport. This change is much more than just increasing the efficiency of cars. Autonomous vehicles bring a time in the history of mankind that is about co-operation. About the co-operation of robots and people. 
In our research, we are examining an area that is less spectacular, but it is inevitable in autonomous transport, the refuel of the cars with no intervention.

\section{CATEGORIZATION OF VEHICLES BY AUTOMATION LEVEL}

Autonomous vehicle, as a concept, is not novel. It was almost 80 years ago, that the Firebird II an experimental vehicle was introduced in 1953, which was capable of tracking on a metal containing test track that was developed specifically for this purpose. This was the first "meaningful car" with then wording. Since then, there has been a lot of progress in technology and by all the scientific facts we know vehicles can move even in a changing environment for a shorter or longer period of time without human intervention.

The great extent of autonomous vehicles will completely transform traffic as well as vehicles. The revolution, which their appearance and propagation mean, also brings a paradigm shift that points much more farther than just economical questions. With the spread of autonomous vehicles a new era will begin.

Many people already talk about the presence of autonomous vehicles. But do we understand on it the same thing? There are some technological steps between the systems of the traditional, human driven cars and the autonomus cars. The most widespread classification is compiled by the SAE association (J3016).

\section{AUTOMATION LEVELS OF AUTONOMOUS CARS}

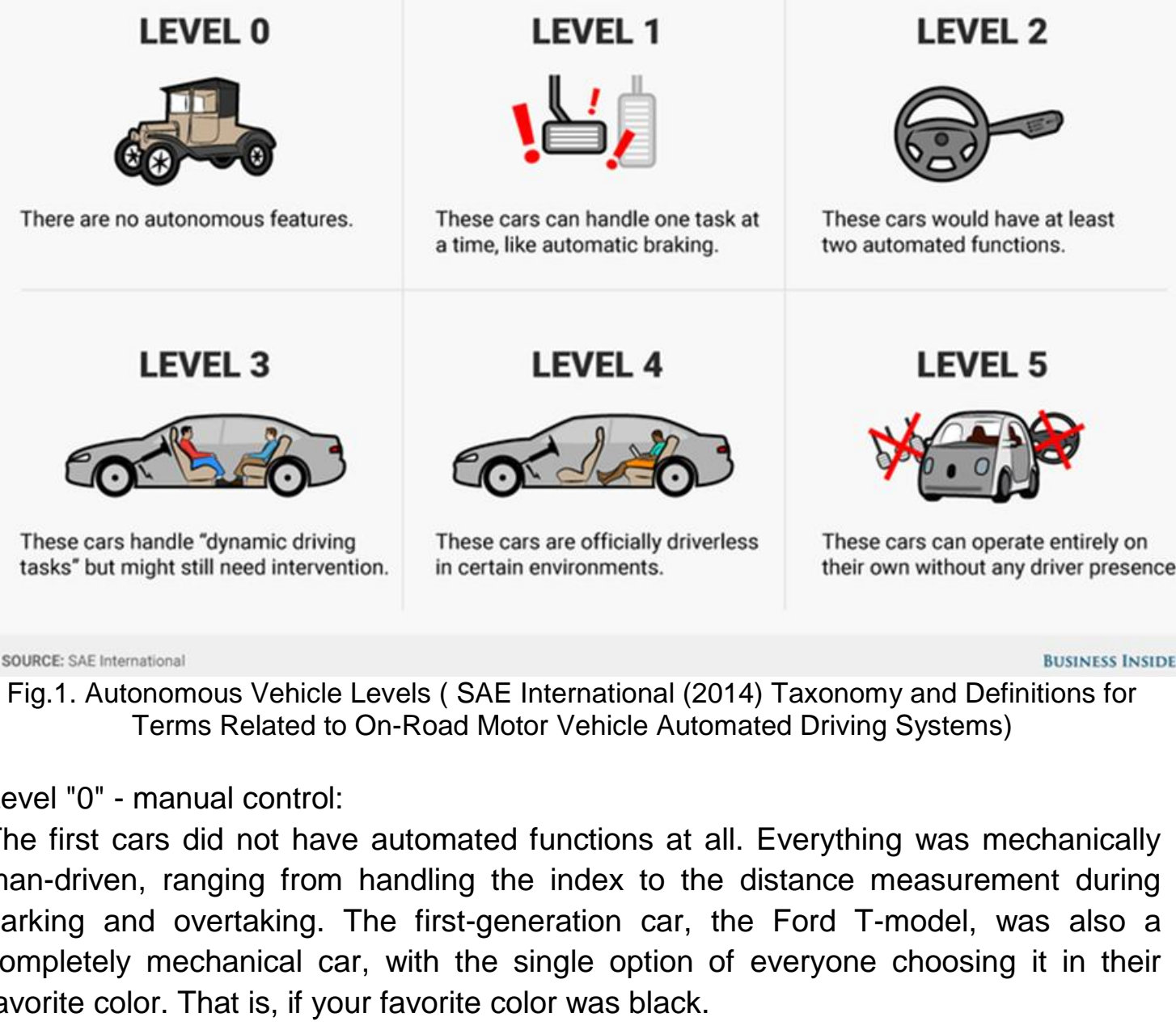


"1" level - driver support systems release:

Nowadays, almost all vehicles taking part in road transport have some kind of driving support system that can intervene as needed. At first this seems strange, but we just do not recognize it because they have become so part of our lives. Let's just think of the European Union mandatory ABS and ESP systems. They observe obscure parameters during transport and intervene if necessary, thereby increasing security. Distant cruise control, traffic sign recognition system, lane automation, etc. are not just for premium cars.

These systems can take control over from time to time, but the driver may override them at any time.

Level 2 - partially automated:

The most representative representation of level 2 is the Tesla, which got a huge, noisy applause for the Model S autopilot system. This system is considered to be an improved management support system that can handle traffic situations considered to be simple on a motorway. Although the autopilot can fully take over the control from the driver when driving a car on a motorway, but the responsibility is at the driver entirely. The phrase "Looking ahead, both hands on the steering wheel" applies to drivers of cars with such automation levels as they have to be ready to take over the control from the car every moment. A Tesla driver in Nevada caused accident when a large insect slammed on the radar sensor, disrupting the operation of the systems relying on it. Unfortuately thus, Tesla - one of the pioneers of this technology - is the first manufacturer to be accountable for the first fatal accident too. In this particular case, on one hand the driver using the autopilot function did not monitor the system with due care and ont he other hand the autopilot system identified a cross-over truck as a harmless highway sign and thus did not brake. Studies3 have shown that drivers using the system overestimate the system's capabilities in great numbers and are not watching the road while traveling. That is why Tesla developed further the system in a way that the autopilot only works until the driver holds his hand on the steering wheel. "Level 3" - highly automated:

Whenever car makers talk about this level or higher, they mention a revolutionary change that many obstacles were to circumvent and even are to circumvent. The decisive difference compared to level "2" is that the vehicle is fully responsible until the driver is not driving. As long as the autopilot is active, the driver has the opportunity to deal with others for a short time, turning his attention from the traffic to another things, for example email reading. Autopilot can only handle simple traffic situations at this level, and only within the right weather conditions. If the system reaches its limits, it still has to provide a certain period of time for the driver to prepare for the take over of the control. This secure handover is a big challange for developers, for a people being busy in most cases needs more time (several seconds) to take over the control. In the meantime, it must also be taken into account that the person who takes it over is not already fully understand the traffic situation, and his failed reactions and decisions might cause an accident.

Audi is the first manufacturer whos new first-generation, mass produced A8 car has these capabilities. However Audi was able to create only a "simple” system that is capable of responding adequately for most of the traffic situations on a motorway. In the future with further development of the system it might be applicable as an urban autopilot. Consumer protection has been concerned about those automated vehicles that are only able to react on a limited way, in simple traffic situations and fail their 
drivers when they actually facing with a near-miss. This definitive disadvantage of the system can only be solved at the next level of automation. According tot he plans, vehicles at level 3 will be designed in a way that they might be transformed fully automated with a simple software upgrade.

"Level 4" - fully automated vehicles:

A fully automated vehicle allows to its driver to read or sleep while the autopilot is driving. However, fully automated systems are still tools that are entrusted to the supervision of the driver as their capabilities are still limited. It handles easily if the driver does not respond to the supervisory pass attempt. In such cases, it will slow down, pull over and stop safely. In case of level 3 and level 4 automation, the technological requirements are not yet well-defined. Therefore, the quality of the system must be very accurately defined in each case. How much time does the system calculate as the necessary time to take over the supervision? How often should the driver indicate his vigilance and attention? What kind of traffic situations can the autopilot handle? Can it handle different weather conditions like fog, misty rain, snow or able to manage darkness?

"Level 5" - driverless systems:

As the name implies, cars belonging to this group do not require human supervision. Their goals are achieved without human intervention and supervision, expecting violation of not even a single traffic rule. The driver is usually just a passenger, who only needs to determine the destination. This means that a driverless vehicle has to interpret environmental events for example a ball rolling in front of the car. It is clear to a human driver that a child might come after the ball and therefore he is going to brake. An autonomous vehicle must also be aware in the same way the additional consequences of sa given event and should be able to prepare for these.

\section{HOW WOULD A ROAD TRIP LOOK LIKE WITH AN AUTONOMOUS VEHICLE?}

To make more tangible the main topic of this article, the significance of the supplement of autonomous cars refuel, imagine how a road trip will look like when mankind would use only autonomous vehicles.

Using a mobile device, we signal our car that we need to travel. Then our car will find us in a safe place, in a parking lot, in a quieter alleyway - as your phone, tablet is in constant contact with it and informs it on your current position - and after getting in the car you can start your journey.

After the beginnings, with the development and spread of technology, the legislative background will probably change in a way which makes possible to remove the wheel, the brake and the accelerator. From this point on, the driver is present as a passenger, and he can turn his attention to completely different things than driving.

This is not the situation currently, as exemplify it Google's self-driving car. Although the car would be able to run without any external intervention, legislation does not allow it to run without steering and pedals, so based on the experience currently the fact that the driver has to hand fully over the control puts more stress on him than the driving itself.

From the moment that the legislative background will permit to travel without the existance of controls in the car, people will consider it as a public transport vehicle, without thinking that they have to pay for insurance, replace rubber, change oil and refuel. This will be especially important for those who wish to use their autonomous 
vehicle not only for urban transport. The question is, that refueling from which of the above mentioned levels become a negligible action to the owner or to the user?

\section{AUTONOMOUS REFUELING}

It will be very important that in the future motor vehicles will be able to solve the supply of motor fuels in an autonomous manner. In the absence of this, taking into account human indolence, the usability of the vehicles would be very limited, and many times should be waited for human intervention. The need for this kind of intervention would take away the aimed goal of the development that travel would be a more careless, stress-free activity.

Today it is almost inconceivable that autonomous vehicles should not only be made electrically in the long run, even though it is technically feasible for a car with a conventional internal combustion engine. For electric cars, refuel is simpler, without touching, with induction charging. The electric charging technology and the charging rate of batteries, however in this case is a bottleneck.

There are already solutions to refilling traditional fossil fuels, but they are typically large machines and bulky, complicated equipment. It is likely that at the same time as the expansion of autonomous vehicles will not be a perfect solution for efficient fuel refueling without human intervention. During the transitional period it will be enough to make cars enable to pay and manage it with the help of a refuel personnel.

Later on, of course, there will be automatic dispensers that are constantly communicating with the vehicles, how much waiting time is expected, how much free capacity is available, which direction the car should fit into the well and indicate if it has reached the desired position and refueling can begin.

Autonomous refueling has many advantages. The most obvious is that the owner does not have to deal with questios like when to refuel, take the car to service, but at the same time can improve the economy indicators in much more abstract areas. It might reduce, for example, post-production logistics costs if the car can be sent by itself directly to the trader, but maintenance costs can also be reduced by always choosing the optimum price / time solution.

In our research work, we are optimizing the refueling of cars powered by hybrid technology taking into consideration the limits of pure electric driving and the expected speed of technological development.

\section{PREDICTION OF CONSUMPTION, FACTORS INFLUENCING CONSUMPTION}

Determining the consumption of cars is the first and most important step to be able to estimate the range. The more precise definition of the range is being studied by more and more studies with the appearance of electric cars due to the limits of energy replenishment and storage.

The determination of the consumption of conventional cars is given by the manufacturers based on the UDC and EUDC cyclical measurements, and the distance what is possible is also calculated on this basis. However, these models ignore the effects of numerous factors that may have a significant impact on consumption, which may result in a $30-45 \%$ difference in actual values compared to the manufacturer's values. In today's comfortable position, when it is natural that a car with a full tank can go up to $1000 \mathrm{~km}$ at any speed, and with the driver's usual style of driving, idealized measurement results are not real, unmanageable problem. The advantage of having an internal combustion engine with regard to the range does not 
require the exact range forecast, it is sufficient to estimate the onboard computer's average consumption only on the average consumption in the last shorter period of travel.

There is an infinite number of pro and contra opinions on the polluting properties of electric cars and other fueled vehicles, weighted by production, disposal processes at the end of the life cycle, local emissions, etc. However, it can be verified without doubts that the efficiency of electric cars is more favorable than the internal combustion engine due to the less moving, overshot parts. $12-30 \%$ of the energy consumed by cars with internal combustion engines is used to move the vehicle, and the other losses from this point of view.

The efficiency of a conventional internal combustion engine and electric cars is shown in the following figure:

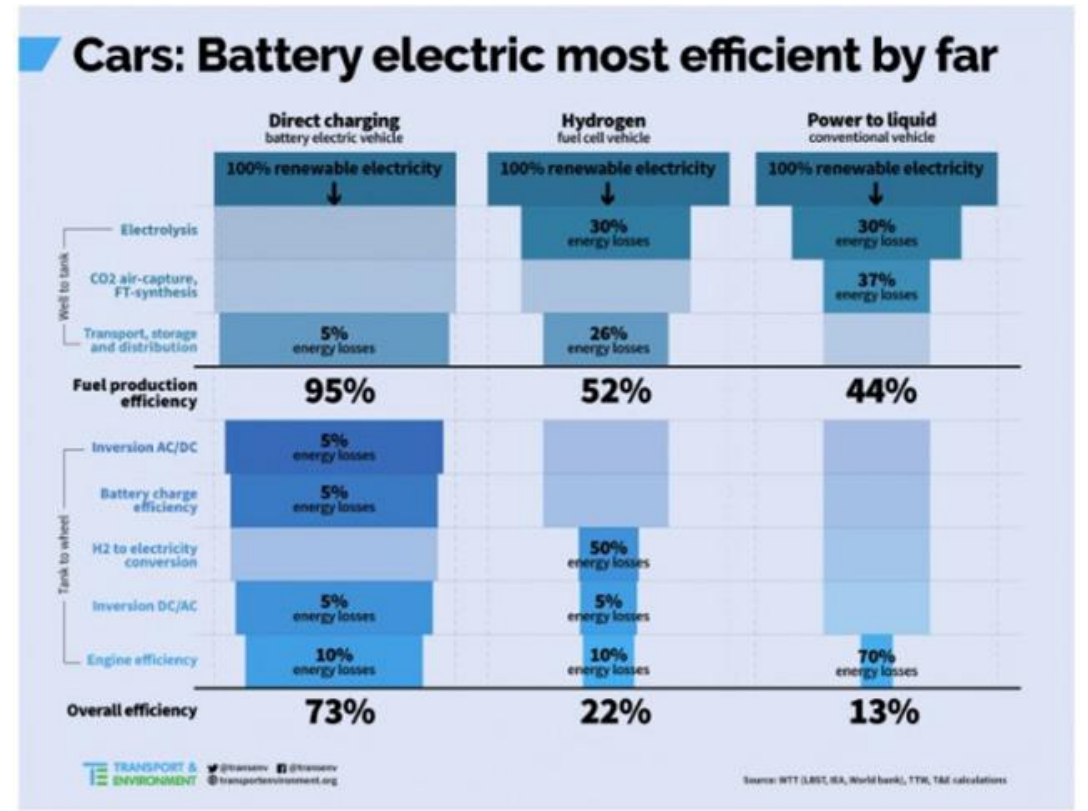

Fig. 2. Effectiveness of vehicles with different propulsion

In case of electric drive, the exact prediction of the range is much more important. Today, even an electric car's actual range is a few hundred kilometers, which is a fraction of its internal combustion engine driven vehicles. This shows that a more accurate assessment of factors influencing consumption and their corresponding interpretation is essential in the future of transport.

In order to increase the usability of autonomous vehicles - since we are thinking mainly of electric drive-, it is not enough to apply the abovementioned rough estimate. All factors affecting consumption with greater extent have to be taken into account. During our work, we grouped and categorized these factors, in which we developed a consumption-enhancing matrix.

\section{INFLUENCING FACTORS}

Factors influencing consumption were performed in a comprehensive, but generalized, grouping. According to these:

- environmental effects

- effects dependent on vehicle condition

- driver-dependent effects

- the effects of the route and the highway 


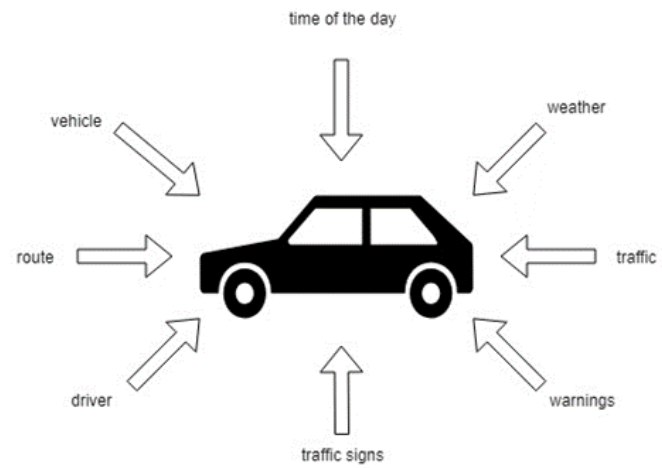

Fig. 3. External factors affecting the car

Table 1

Modeling of external factors affecting the consumption of a car

\begin{tabular}{|c|c|c|c|c|c|c|}
\hline & low & & middle & & high & \\
\hline environmental effects & dry highway & $0,7 \%$ & wet highway & $1,7 \%$ & wind & $6,6 \%$ \\
\hline \multirow{2}{*}{\begin{tabular}{|l|} 
effects dependent on \\
vehicle condition
\end{tabular}} & first or rear wheel drive & $0,6 \%$ & retreaded wheel & $1,8 \%$ & 4 wheel drive & $3,3 \%$ \\
\hline & tire pressure to low & $0,2 \%$ & & & wheel alignment & $5,9 \%$ \\
\hline \multirow{2}{*}{ driver-dependent effects } & & & number of brakings & $1,4 \%$ & steady driving style & $5,0 \%$ \\
\hline & & & slightly exceeded the speed limit & $2,6 \%$ & clima & $3,0 \%$ \\
\hline the effects of the route & material & $0,5 \%$ & surface & $1,2 \%$ & easy or heavy road & $6,6 \%$ \\
\hline and the highway & & & & & urban environment & $33,0 \%$ \\
\hline
\end{tabular}

\section{SUMMARY OF ADDITIONAL RESEARCH DIRECTIONS}

In our work, we investigate which factors influence should be take into consideration in the consumption forecast and what are those which not useful for modeling.

One of the researches on this subject was the study of the maximum distance, the number of filling stations along the road and the autonomous decisions and suggestions made by the generated algorithm, based on the time spent on refueling. Its outputs could be easily varied by changing the clustering characteristics of the filling station or by modifying the urgency of refueling. In the course of our research, we will also use the experience gained in this way with the available data of the terrain and the data on the general state of the car from the vehicle database.

The model underlying the forecast is used to reconstruct data obtained experientially. Measurements are carried out on a closed test track that simulates real-life conditions, with random selected hybrid driven vehicles.

In order to determine the energy balance of a motor vehicle more precisely, the output and input values must be measured in many points. During the measurement, energy flows between energy sources and consumers must be recorded.

A possible measurement switch for the energy consumption and thus the consumption enhancing effects can be seen in the figure below. 


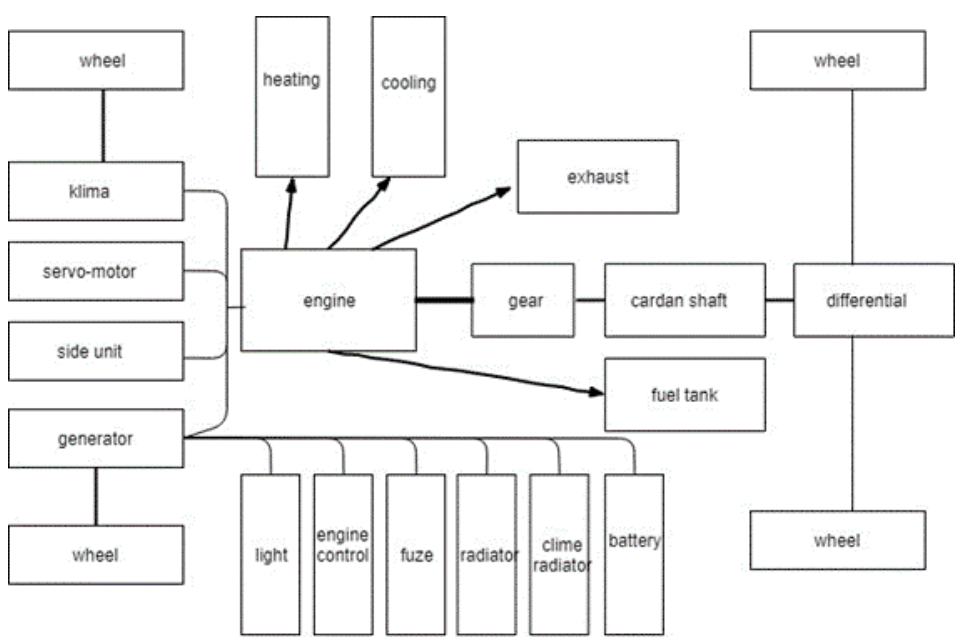

Fig. 4. Schematic view of measurements on the test track

After the model is completed, we will have a simulation tool that determines the range by dynamically taking into account the effects of the factors influencing consumption and individually specifying the filling station and filling stations where the vehicle is able to pick the optimum fuel mix mix according to the criteria given by the passenger.

\section{REFERENCES}

Xu, Q., Yang. K., Peng, S., Hong, L., 2018. A Distance-Adaptive Refueling Recommendation Algorithm for Self-Driving Travel. March, International Journal of Geo-Information 7(3):94. DOI:10.3390/ijgi7030094

LKW-Einkauf, Logistik inside.

https://www.gefahrgut-

nline.de/fm/3576/LOGISTIK_inside_LKW_Dieselverbrauch.pdf

Delp, M., Autonomous vehicle refueling locator. US9400500B2. https://patents.google.com/patent/US9400500

Csiszár, Cs,, Csonka, B., Földes, D., Wirth, E., Lovas, T., 2018. Az országos átjárhatóságat biztositó elektromos villám töltő-állomások helyszínét kijelölő módszer. Közlekedéstudományi szemle, Közlekedéstudományi szemle, 68 (1-4).

Jakobson, C., 2016. Einflussgrößen auf den Kraftstoffverbrauch. Teil 1 Limousinen, Der Autokritiker.

http://der-

autokritiker.de/technik/151016_Einflussgr\%C3\%B6\%C3\%9Fen\%20auf\%20den\% 20Kraftstoffverbrauch\%20Limousinen.pdf

Gołębiewski, W. Stoeck, T., 2014. Prediction of the Mileage Fuel Consumption of Passenger Car in the Urban Driving Cycle. Teka Commission of motorization and energetics in agriculture, Vol. 14, No. 3, 17-24.

https://www.bussgeldkatalog.org/sprit-sparen/sparsame-autos/ - 2018.12.01

https://www.marktundmittelstand.de/themen/nutzfahrzeuge/die-zukunft-des-autos-istnicht-nur-elektrisch-1262591/ - 2018.11.28

Almér, H., 2015. Machine learning and statistical analysis in fuelconsumption prediction for heavy vehicles. Master's Thesis at CSC. https://www.divaportal.org/smash/get/diva2:846386/FULLTEXT01.pdf

Ritz, J., Mobilitätswende - Autonome Autos erobern unsere Strassen 5,6. Springer Verlag. ISBN 978-3-658-20953-7 
Rabl, H., Makarenko, I., 2008. Spritsparendes Autofahren University of Applied Sciences Regensburg. Wissenschaftszentrum Straubing, 8.

Rumbholz, P., Untersuchung der Fahrereinflüsse auf den Energieverbrauch und die Potentiale von verbrauchsreduzierende Verzögerungsassistenzfunktionen bei PKW.

www.sae.org/misc/pdfs/automated_driving.pdf

www.vda.de/de/themen/innovation-und-technik/automatisiertes-fahren/automatisiertes -fahren.html

Polak, F., 2018. REV's Hybrid Vehicle Range Modeling. Journal of KONES Powertrain and Transport, Vol. 25, No. 2, 281-286.

DOI: 10.5604/01.3001.0012.2814

Varga, B., Iclodean, C., Mariasiu, F., 2016. Energetic Efficiency of Vehicles Equipped with Hybrid and Electric Drive Systems. Electric and Hybrid Buses for Urban Transport. DOI: 10.1007/978-3-319-41249-8_2

Török, A., Török, A., Heinitz, F., 2014. Usage of Production Functions in the Comparative Analysis of Transport Related Fuel Consumption. Transport and Telecommunication Journal, 15(4), 292-298. https://doi.org/10.2478/ttj-20140025

Ildarkhanov, R., 2017. The Calculation of the Fuel Cost for a Car. Periodica Polytechnica Transportation Engineering. doi: https://doi.org/10.3311/PPtr.10553

Szalay, Z., Tettamanti, T., Esztergár-Kiss, D., Varga, I., Bartolini, C., 2018. Development of a Test Track for Driverless Cars: Vehicle Design, Track Configuration, and Liability Considerations. Periodica Polytechnica Transportation Engineering, 46(1), 29-35. doi: https://doi.org/10.3311/PPtr.10753 